University of Nebraska - Lincoln

DigitalCommons@University of Nebraska - Lincoln

\title{
Nonylphenol Stimulates Fecundity but not Population Growth Rate (ג) of Folsomia candida
}

\author{
T. H. Widarto \\ Roskilde University, thw@ruc.dk \\ P. H. Krogh \\ National Environmental Research Institute, Department of Terrestrial Ecology, Denmark \\ Valery E. Forbes \\ University of Nebraska-Lincoln, veforbes@umn.edu
}

Follow this and additional works at: https://digitalcommons.unl.edu/biosciforbes

Part of the Pharmacology, Toxicology and Environmental Health Commons

Widarto, T. H.; Krogh, P. H.; and Forbes, Valery E., "Nonylphenol Stimulates Fecundity but not Population Growth Rate $(\lambda)$ of Folsomia candida" (2007). Valery Forbes Publications. 24.

https://digitalcommons.unl.edu/biosciforbes/24

This Article is brought to you for free and open access by the Papers in the Biological Sciences at DigitalCommons@University of Nebraska - Lincoln. It has been accepted for inclusion in Valery Forbes Publications by an authorized administrator of DigitalCommons@University of Nebraska - Lincoln. 


\title{
Nonylphenol Stimulates Fecundity but not Population Growth Rate $(\lambda)$ of Folsomia candida
}

\author{
T. H. Widarto, ${ }^{1}$ P. H. Krogh, ${ }^{2}$ Valery E. Forbes ${ }^{3}$
}

1. Department of Biology, Bogor Agricultural University, Indonesia, and Department of Life Sciences and Chemistry, Roskilde University, Denmark; corresponding author, E-mail address thw@ruc.dk

2. National Environmental Research Institute, Department of Terrestrial Ecology, Denmark

3. School of Biological Sciences, University of Nebraska-Lincoln, Lincoln, Nebraska, USA (2011); formerly of

Department of Life Sciences and Chemistry, Roskilde University, Denmark (2007)

\begin{abstract}
The toxicity of nonylphenol (NP) to springtails was pronounced at $40 \mathrm{mg} / \mathrm{kg}$ dry weight soil, at which no animals survived. Body length and fecundity were the individual life-history traits significantly stimulated by sublethal concentrations of NP during a 64-day experiment. However, the effects of NP on these traits did not result in a statistically significant increase in population growth rate $(\lambda)$. Decomposition analysis indicated that fecundity was the main contributor to the (non-significant) changes observed in $\lambda$. However, since the elasticity of fecundity was very low, large changes in fecundity resulted in a minimal effect on $\lambda$. Juvenile survival had the highest elasticity of all traits, but was not affected by NP, and therefore did not contribute to effects on $\lambda$. This study confirms previous studies showing that effects of chemicals on individual life-history traits are attenuated at the population level and that $\lambda$ is an appropriate endpoint for ecotoxicological studies.
\end{abstract}

Keywords: elasticity, life-history, population dynamics, hormesis, Folsomia

\section{Introduction}

Ecotoxicology aims to understand and predict the effects of xenobiotics on ecological systems, i.e., on populations, communities and ecosystems. However, in practice the majority of tests used for regulatory and legislative purposes focus on individual-level responses that are relatively easy, inexpensive and rapid to measure. These advantages enable toxicity tests to be conducted for many chemicals on different species of organisms by many laboratories routinely (Laskowski, 2001). However, accurately extrapolating such test results to ecologically relevant consequences remains an important challenge.

It is well known that chemical exposure-response relationships of individual life-history traits may differ markedly from each other and from the exposure-response relationship for population growth rate. For example, the response of individual reproduction to chemical exposure may either be more (e.g. Scott-Fordsmand et al., 1997; Van Gestel and Hensbergen, 1997; Hood et al., 2000) or less sensitive than individual growth rates (e.g. Van Straalen et al., 1989). In general, juveniles are more sensitive than adults to toxicant exposure (Stark and Banken, 1999). However, effects on juvenile survival do not always lead to reductions in population growth rate since survivors may compensate for the lost individuals by increasing their own reproduction (Walthall and Stark, 1997; Bechmann, 1999). Kammenga et al. (1996) showed that the most toxicant-sensitive trait (the reproductive period) did not result in any significant effect on population growth rate of the nematode, Plectus acuminatus, whereas effects on a relatively toxicantinsensitive trait (time to first reproduction) had a large influence on population growth rate. Jensen et al. (2001) observed large reductions in the most sensitive individual life-history trait (reproductive output) after cadmium exposure, which resulted in smaller, though significant, re- 
ductions in population growth rate of the snail Potamopyrgus antipodarum. Effects at the individual level may even be in opposite directions to those occurring at the population level. For example, despite increased growth of juvenile blowflies, Lucilia sericata, in response to exposure to sublethal concentrations of cadmium, population growth rate declined (Moe et al., 2001). These studies highlight the complex relationship between toxicant effects on individual performance versus population dynamics.

The present study was designed to explore the relationships between individual-and population-level responses of a terrestrial invertebrate to a toxicant. We measured the effects of nonylphenol (NP) on individual life-history traits of the springtail (Folsomia candida) and, using a two-stage life-cycle model (Calow and Sibly, 1990), we analyzed the effects of NP on population growth rate $(\lambda)$. To determine the relative contribution of the life-history traits to the observed effects of NP on $\lambda$ and to examine the (relative) demographic sensitivity of $\lambda$ to changes in each of the lifehistory traits, we performed decomposition and elasticity analysis, respectively.

NP is a chemical contained in many industrial, household and agricultural products as NP ethoxylates. In the environment, NP will be produced again by aerobic degradation of its ethoxylates (Nimrod and Benson, 1996). Numerous studies have examined the effects of NP on many species of mostly aquatic animals and have indicated that NP is not only highly toxic (Granmo et al., 1989), but also may have endocrine disrupting properties at sublethal exposure concentrations (Yadetie et al., 1999). In addition, NP is also bioaccumulated (Johnson et al., 1998) and resists degradation under anaerobic conditions (Maguire, 1999). Studies on effects of NP on soil animals are scarce despite the fact that NP may enter the terrestrial environment mainly through sludge produced in wastewater treatment plants that is subsequently used as fertilizer or (though to a lesser degree) through pesticides utilizing NP as an adjuvant.

Folsomia candida is a common, soil-dwelling, wingless, unpigmented and parthenogenetic insect that is widely distributed around the globe, abundant and plays an important role in soil ecosystems. Because of its abundance and distribution, as well as its ease of culture and short reproductive cycle, the springtail is one of the most extensively used animals in terrestrial ecotoxicology.

\section{Materials and methods}

\subsection{Test animals}

A laboratory culture of Folsomia candida established at the National Environmental Research Institute (NERI), Denmark was used for this experiment. In NERI, field-collected animals were maintained as stock cultures in Petri dishes filled with a substrate of moistened plaster of Paris and charcoal. They were kept at a constant temperature of $20^{\circ} \mathrm{C}$ and under a $12 \mathrm{~h} / 12 \mathrm{~h}$ light/dark regime. New substrates with dried yeast as fresh food were prepared every 2-4 weeks and added ad libitum to the cultures. Prior to the experiment juveniles were obtained by hatching eggs collected from stock cultures. Only 0-1-day-old juveniles were employed for this experiment.

\subsection{Soil preparation and application procedures}

Light-textured, sandy loam agricultural soil from Askov Experimental Station, Denmark was utilized for the experiment. The soil was dried and defaunated at $80^{\circ} \mathrm{C}$ and sieved through $1 \mathrm{~mm}$ mesh. For the first 2 weeks, we used soil sieved to $250 \mathrm{~mm}$ to ease measurement of the very small juveniles. According to Sverdrup et al. (2002) this same soil (though sieved to $2-\mathrm{mm}$ ) consisted of $38.4 \%$ coarse sand $(200-2000 \mu \mathrm{m}), 23.6 \%$ fine sand $(63-200 \mu \mathrm{m}), 10 \%$ coarse silt $(20-63 \mu \mathrm{m}), 12.3 \%$ fine silt $(2-20 \mu \mathrm{m})$, and $13 \%$ clay $(<2 \mu \mathrm{m}), 2.8 \%$ humus and $1.6 \%$ organic carbon, had a $\mathrm{pH}_{\mathrm{H}_{2} \mathrm{O}}$ of 6.2 , a density of $1.135 \mathrm{~g} / \mathrm{cm}^{3}$ dry soil and a total cation exchange capacity of 8.14 meq/100 g soil.

NP (Aldrich, Cat. no. 29.005.8, 100\% pure) concentration series were prepared by diluting a stock solution in acetone (J. T. Barker, Hayward, CA, USA). The stock solution was prepared corresponding to the highest test concentration, $40 \mathrm{mg} / \mathrm{kg}$ dry weight (dw). To contaminate the soil, $225 \mathrm{ml}$ solution was added and mixed thoroughly into $1.5 \mathrm{~kg}$ of the soil. Pure acetone was used for the control soil. The solvent was evaporated for $24 \mathrm{~h}$ under a fume hood. The dried contaminated soils were then put in plastic bags and stored in a deep freezer $\left(-20^{\circ} \mathrm{C}\right)$ until use. Just prior the start of the experiment, the soil was moistened by 15\% distilled water (by weight).

All effects of NP in the present study are based on nominal concentrations added to soils. Analytical measurements of these same soils were performed for a separate study with Dendrobaena octaedra and showed that the concentration of NP in the soil was relatively unchanged after being kept $1 \frac{1}{2}$ years in a deep freezer $\left(-20^{\circ} \mathrm{C}\right)$ (Widarto et al., 2004). Weekly changing of the soils ensured that the springtails were exposed to a relatively constant concentration of NP throughout the experiment.

\subsection{Experimental set-up}

Nunclon multi-well dishes (NUNC A/S, Roskilde, Denmark), with 24 circular wells (diameter $=1.5 \mathrm{~mm}$ ) were used to keep individual springtails. Before new multi-well dishes were used, they were treated with destaticizer to reduce static electricity. Each well was filled with $2.5 \mathrm{~g}$ soil containing $15 \%$ deionized water. The soil was compressed with a pestle to obtain a firm and even surface, which aided measurement by preventing the animals from hiding in crevices. Care was taken to avoid an excessive pressure that makes the surface wet. After adding 2-3 granules of dried baker's yeast (Saccharomyces cerevisae) as food in each well, a double layer of aluminum foil was used to cover all wells to prevent the springtails from escaping. To reduce water evaporation, the multi-well dishes were covered with thick cardboard glued to the original cover. All multiwell dishes were put in a closed plastic box layered with wet tissue paper at the bottom. The soils were renewed once a week during which no water was added to the substrates to minimize disturbance. When the animals started to produce eggs, only the adults were transferred into new soils. The eggs were left in the old soils until they hatched.

Five sublethal concentrations plus a control were used: $0,8,16$, 24,32 , and $40 \mathrm{mg} / \mathrm{kg} \mathrm{dw}$ soil after a range-finding test found that only $42 \%$ of the juveniles survived $45 \mathrm{mg} / \mathrm{kg}$ dw soil. One neonate juvenile (0-1-day-old) was added to each well of the multi-well dishes. Twelve replicates per treatment were used.

Digital image processing equipment (DIP) was used to record individual body lengths without disturbing the animals during the observation. DIP consisted of a video camera mounted on the ocular lens of a stereomicroscope that was connected to a monitor and a computer. Pictures of living specimens were recorded on the hard disk or on videotape and measured manually.

We measured body length from the posterior end of the abdomen to the anterior end of the head between the antennae (in the moving position). Body lengths were measured using the image analysis software Sigma Scan Pro (v.5, SPSS, Chicago, IL). Survival, molting, 
egg production and egg development were monitored. The animals were checked every day until the end of the experiment to determine molting since this species eats its own exuviae. Newly hatched neonates were quantified by counting the number of empty eggshells.

Twelve replicates were employed for survival and body length, however, as the animals got older and some of them died, the number of replicates decreased. For reproductive endpoints, six replicate individuals were chosen randomly from the original 12 individuals.

\subsection{Population growth $(\lambda)$, elasticity and decomposition analysis}

To calculate $\lambda$ for each treatment we fit the life-history data to a twostage model (Calow and Sibly, 1990):

$$
1=n S_{\mathrm{j}} \lambda^{-\mathrm{tj}}+S_{\mathrm{a}} \lambda^{-\mathrm{ta}},
$$

where $n$ is the number of hatched eggs per brood, $S_{\mathrm{j}}$ represents juvenile survival (the probability that a juvenile survives from birth to first reproduction), $S_{\mathrm{a}}$ represents adult survival (i.e. the average probability that an adult survives between census days), $t_{\mathrm{j}}$ is the average time to first reproduction, and $t_{\mathrm{a}}$ time between broods.

Elasticity analysis was carried out to determine the relative sensitivity of population growth rate $(\lambda)$ to changes in each of the lifehistory traits contributing to it. To measure the elasticity we employed the equation: $e_{\mathrm{a}}=(a / \lambda)(\mathrm{d} \lambda / \mathrm{d} a)$, where $a$ is a life-history trait and $\mathrm{d} \lambda / \mathrm{d} a$ is the sensitivity of $\lambda$ to changes in the particular life-history trait, $a$ (Caswell, 2001). The elasticity was calculated based on Equations (3)-(7) in Forbes et al.(2001) and $T=n S_{\mathrm{j}} t_{\mathrm{j}}+S_{\mathrm{a}} t_{\mathrm{a}} \lambda_{\mathrm{j}} \mathrm{t}_{\mathrm{a}}$. Decomposition analysis was carried out to determine how much each life-history trait contributed to the observed treatment effects on $\lambda$. The contributions of treatment effects on each life-history trait to the overall effect on $\lambda$ were calculated following Caswell (1989) and Levin et al. (1996). For the elasticity and decomposition analyzes, juvenile survival $\left(S_{\mathrm{j}}\right)$ is expressed on a per unit time basis in order to make this trait independent of the length of the juvenile period $\left(t_{\mathrm{j}}\right)$. For these analyses we used $p_{\mathrm{j}}$ where $S_{\mathrm{j}}=p_{\mathrm{j}}{ }_{\mathrm{j}}$.

\subsection{Statistical analysis}

Since, there were no survivors in the highest concentration $(40 \mathrm{mg}$ $\mathrm{NP} / \mathrm{kg}$ ), all statistical analyses were carried out without including this concentration. Repeated measures analysis of variance (ANOVA) was used to test for treatment effects on body weight and egg production. One-way ANOVA was used to test for treatment effects on time to first reproduction, development time and egg viability. Tukey's pairwise comparisons were performed when the ANOVA detected significant treatment effects. Effects were considered significant when $p \leq 0.05$, and considered marginally significant when $0.05<p \leq 0.01$. All statistical analyses were performed with SYSTAT Version 10.

The effects of NP on population growth rate were analyzed by calculating 95\% confidence intervals around $\lambda$ for each concentration using an analytical method (Sibly et al., 2000). The calculation of the confidence intervals was performed by calculating the total variance of $\lambda$, which is the sum of the variance contributions from each of the five life-history traits contributing to $\lambda$. The square root of the total variance is the standard error of $\lambda$. Observed differences between the population growth rates were deemed significant if there was no overlap between the confidence intervals.

\section{Results}

\subsection{Survival}

Except in the highest concentration (40 mg/kg), all juveniles of Folsomia candida survived until first reproduction. In the highest concentration, springtails survived for only
2-6 days. During the adult period, NP showed no clear concentration-response effect on survival. Excluding the highest concentration, survival was marginally impaired by NP $(p=0.071)$, but Tukey's pairwise comparisons showed no differences between any two concentrations $(p>0.05)$.

\subsection{Growth}

Body length of $F$. candida increased with time following a sigmoid growth curve. During the 64-day experiment, body length increased significantly from an average of 0.40 to $2.10 \mathrm{~mm}$ (effect of time $p<0.01$ ) with maximum length attained at 30-34 days of age (Figure 1). NP also affected body length $(p<0.01)$ and the interaction between time and NP was significant $(p=0.002)$.

NP stimulated growth at the lower concentrations (i.e., up to $24 \mathrm{mg} / \mathrm{kg}$ ) and at $32 \mathrm{mg} \mathrm{NP} / \mathrm{kg}$, body size was less than the control only for days 20 and 30 (Figure 1). After 30 days of age, when the body length of springtails reached between $2.04 \mathrm{~mm}$ (the lowest) in the control and $2.20 \mathrm{~mm}$ (the highest) in the $16 \mathrm{mg} / \mathrm{kg}$ concentration, effects of NP were not detectable.

\subsection{Molting}

F. candida released their first exuviae (cuticle) at the age of 3-4 days. NP reduced the time to first molt $(p=0.01)$. Tukey's pairwise comparison test showed that time to first molt in $16 \mathrm{mg} / \mathrm{kg}(p=0.027)$ was significantly shorter than in the control. Marginally significant differences were observed between the control and $24 \mathrm{mg} / \mathrm{kg}(p=0.079)$ and between 16 and $32 \mathrm{mg} / \mathrm{kg}(p=0.063)$. In the highest concentration $(40 \mathrm{mg} / \mathrm{kg})$, only two of 12 individuals molted. After the first exuviae, F. candida cast off its cuticle every 3-4 days, and NP did not affect this molting period ( $p$ $=0.12$ ). Thus, during the 64-day experiment, 16 moltings were recorded on average.

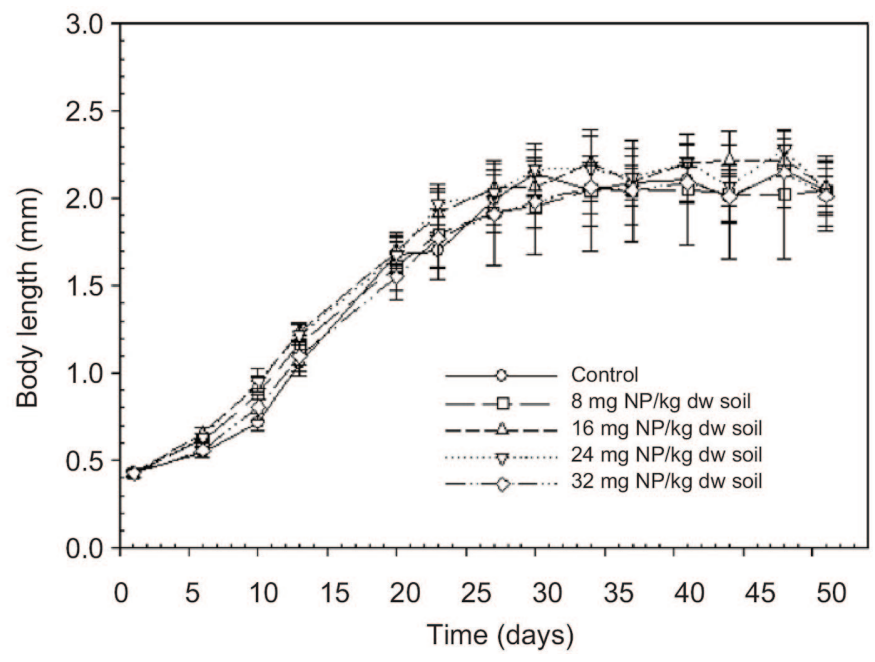

Figure 1. The growth of Folsomia candida on Askov sandy loam soil, expressed as body length (mean \pm SEM) during 64 days of exposure to nonylphenol. 
a

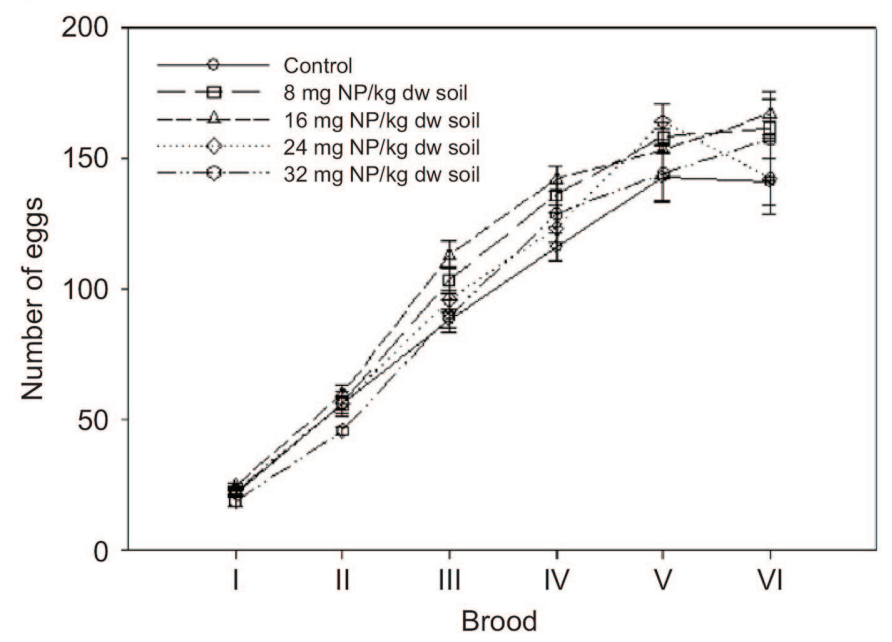

b

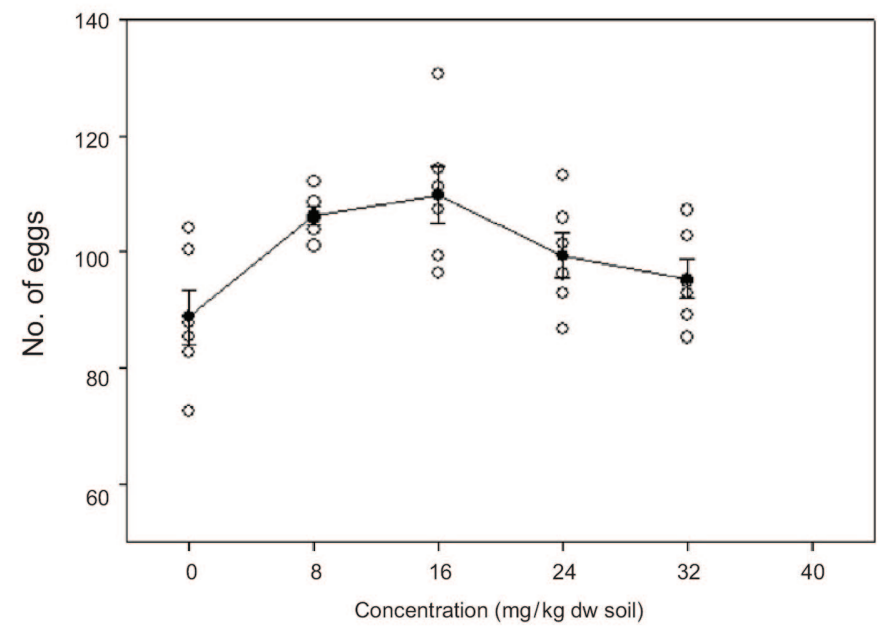

Figure 2. (a) Mean number of eggs of Folsomia candida on Askov sandy loam soil produced per individual per brood during 64 days of exposure to nonylphenol. Error bars = SEM. (b) Mean number of eggs of Folsomia candida on Askov sandy loam soil per individual produced during 64 days of exposure to nonylphenol (open circles represent individual data; filled circles represent means \pm SEM).

\subsection{Reproduction}

Springtails reproduced for the first time at an age of 1516 days (Figure 2a), and we did not detect any effects of $\mathrm{NP}$ on this trait $(p=0.87)$. The springtails then produced eggs every 7-8 days, and no effect of NP was detected on the time between broods $(p=0.98)$. During the 64-day experiment, F. candida produced an average of 6-7 broods per individual.

A total of six broods was analyzed from each of six females per treatment. Whereas the early broods contained an average of 20-25 eggs per individual, brood size increased markedly with age $(p<0.001)$ reaching approximately 150 eggs per brood in the sixth brood. The aver- age number of eggs per individual, pooled over the six broods, (Figure 2b) showed that NP significantly affected egg production in the springtails $(p=0.006)$. Tukey's pairwise comparison indicated that individuals treated with 8 and $16 \mathrm{mg} \mathrm{NP} / \mathrm{kg}$ produced a significantly larger number of eggs than those in the control $(p=0.031$ and 0.007 , respectively), whereas the two higher concentrations produced similar numbers of eggs as the control $(p=0.33$ in 24 $\mathrm{mg} \mathrm{NP} / \mathrm{kg}$ and $p=0.761$ in $32 \mathrm{mg} \mathrm{NP} / \mathrm{kg}$ ).

Separate ANOVAs were carried out to examine the effect of NP on each brood, and the results showed that NP had significant or marginally significant effects on the average number of eggs produced per individual in the first four, but not the last two broods $(p=0.021,0.07,0.008,0.01$, $0.38,0.36$, in order from the first to the sixth brood). Springtails in the $16 \mathrm{mg} \mathrm{NP} / \mathrm{kg}$ treatment generally produced more eggs than those in the other concentrations, including the control. None of the broods produced by the highest treatment group (32 mg NP/ $\mathrm{kg}$ ) differed from the control group ( $p>0.05$ for all comparisons).

\subsection{Egg viability and development time}

We tested the first five broods produced for effects of NP on egg viability and detected a significant effect only in the second brood ( $p=0.69,<0.01,0.54,0.08,0.91$, respectively). When we pooled the data from each brood, the effect was not significant $(p=0.68)$. Most eggs (average $>95 \%$ ) hatched in all treatments, and one batch of eggs in the 16 $\mathrm{mg} / \mathrm{kg}$ had a hatching success of $100 \%$. The lowest hatching success was $80.5 \%$ recorded from a control brood.

Development time was calculated from hatched eggs (eggs that failed to hatch were excluded). Eggs hatched after an average of 9-10 days. ANOVAs performed on the individual broods showed that NP did not have any effects on egg development time $(p>0.05)$. When pooled data were analyzed and Tukey's pairwise comparisons performed, a significant difference was only detected between 8 and $24 \mathrm{mg} / \mathrm{kg}(p=0.023)$.

\subsection{Population growth rate $(\lambda)$, decomposition and elas- ticity analysis}

All $\lambda^{\prime}$ s in the control and the NP treatments were greater than one (Figure 3 ). We observed small increases in $\lambda$ as the $\mathrm{NP}$ concentrations increased up to $16 \mathrm{mg} / \mathrm{kg}$ followed by decreases at higher concentrations. $\lambda$ increased by $0.46 \%$ (at $8 \mathrm{mg} \mathrm{NP} / \mathrm{kg}$ ) and by $1.55 \%$ (at $16 \mathrm{mg} \mathrm{NP} / \mathrm{kg}$ ) (Table 1). The increase in $\lambda$ in $16 \mathrm{mg} / \mathrm{kg}$ resulted mainly from the positive response of fecundity that contributed $98 \%$ to the effect on $\lambda$. Based on the calculation of $95 \%$ confidence intervals, however, $\lambda$ was not significantly different between the concentrations.

Since $100 \%$ of the juveniles survived in all treatments, juvenile survival did not make any contribution to the (non-significant) effect on $\lambda$. Decomposition analysis of the two-stage model revealed that the effect of NP on $\lambda$ was mostly attributable to the effect on fecundity (between $61 \%$ and $98 \%$ ) whereas the effect on time to first reproduction 


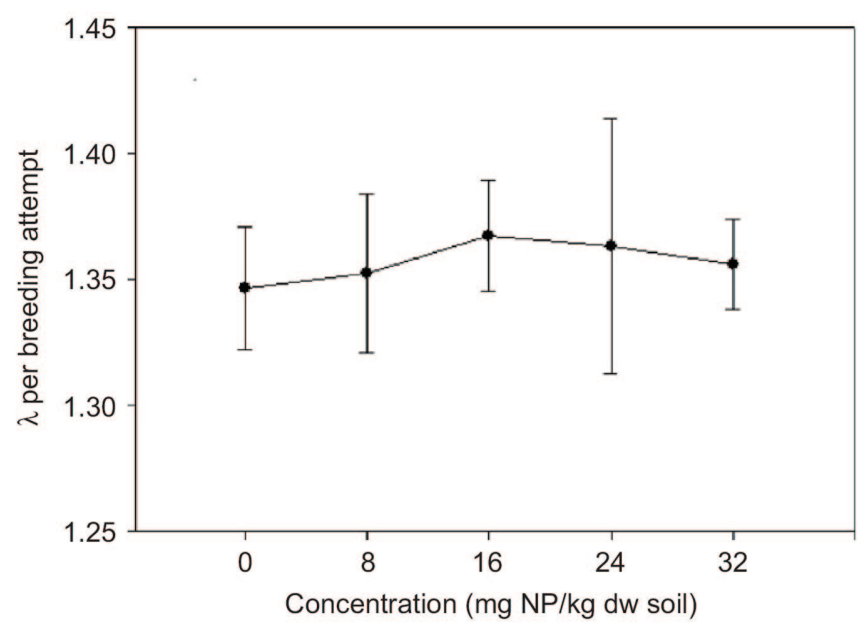

Figure 3. Population growth rate $(\lambda)$ of Folsomia candida on Askov sandy loam soil exposed to nonylphenol. Error bars represent $95 \%$ confidence intervals.

contributed between $0 \%$ and $35 \%$ to the total change in 1 (Table 1). Time between broods contributed between $2 \%$ and $12 \%$, and adult survival contributed very little to the change in $\lambda$ since nearly all adults survived.

Figure 4 shows the relative sensitivity (elasticity) of population growth rate to changes in each life-history trait of $F$. candida. For this life cycle, $\lambda$ was the most sensitive to changes in juvenile survival probability $\left(S_{\mathrm{j}}\right)$ and insensitive to changes in adult survival probability $\left(S_{\mathrm{a}}\right)$ (i.e., elasticity of $S_{\mathrm{a}}$ was only one hundredth of that of $S_{\mathrm{j}}$ ). The relative sensitivity of $\lambda$ to changes in time to first reproduction $\left(t_{\mathrm{j}}\right)$ was about one third that of juvenile survival $\left(S_{\mathrm{j}}\right)$. The relative sensitivity of $\lambda$ to changes in fecundity $n$ and time between broods $\left(t_{\mathrm{a}}\right)$ was ten-and two-fold higher, respectively, than to changes in adult survival probability $\left(S_{\mathrm{a}}\right)$. Exposure to different concentrations of NP did not change the elasticity patterns among traits.

\section{Discussion}

\subsection{Linking individual-to population-level responses}

This study showed that individual life-history traits of $F$. candida responded differently to exposure to NP and that significant stimulatory effects of a chemical at the individual level do not necessarily result in significant effects at

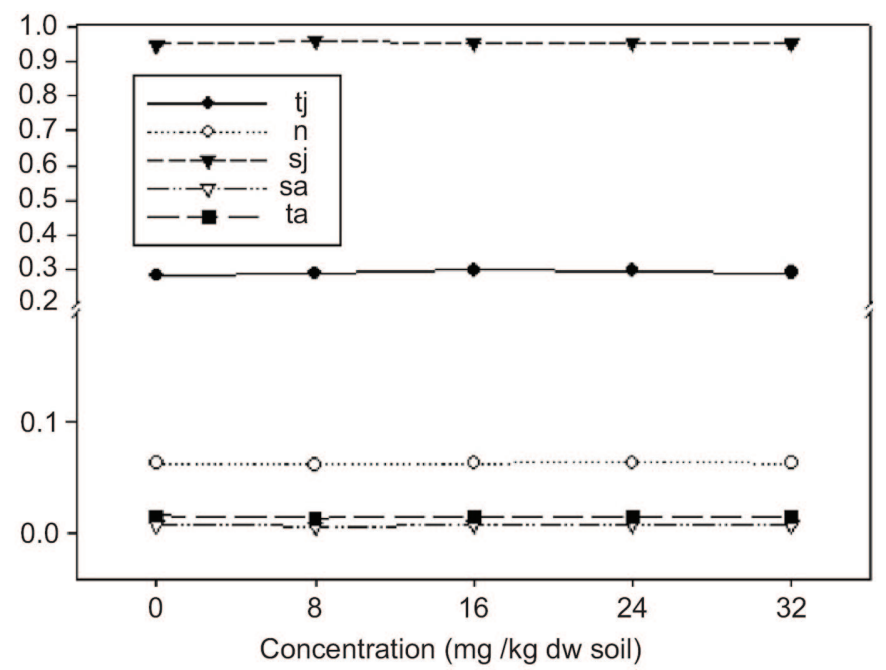

Figure 4. Elasticity of time to first reproduction $\left(t_{\mathrm{j}}\right)$, egg production $(n)$, juvenile survival $\left(S_{j}\right)$, adult survival $\left(S_{\mathrm{a}}\right)$, and time between broods $\left(t_{\mathrm{a}}\right)$ of Folsomia candida on Askov sandy loam soil at different nonyphenol concentrations. Note that to aid comparison these are values of elasticity, since increases in $t_{\mathrm{j}}$ and $t_{\mathrm{a}}$ have a negative effect on $\lambda$ whereas increases in $n, S_{\mathrm{j}}$ and $S_{\mathrm{a}}$ have a positive effect on $\lambda$.

the population level. At the highest exposure concentration (40 $\mathrm{mg} / \mathrm{kg} \mathrm{dw}$ soil), no juveniles survived the treatment, and therefore none of the other traits could be assessed. At sublethal concentrations (up to $32 \mathrm{mg} / \mathrm{kg} \mathrm{dw}$ soil), traits such as growth, time to first molting and fecundity were stimulated by NP exposure, whereas no effects of NP were observed on time between molts, time to first reproduction, time between broods, number of broods, egg viability or egg development time. Integrating the individual-level effects via a two-stage life-cycle model indicated that the overall effect of NP on population growth rate, $\lambda$, was not statistically significant and suggests that effects at the individual level are attenuated at the population level.

By using elasticity analysis we were able to explore the sensitivity of $\lambda$ to changes in the life-cycle traits contributing to it (Caswell, 1989). With this analysis we estimated the proportional change in $\lambda$ resulting from a proportional change in a given life-history trait, holding all other traits constant. Under the laboratory conditions used in the present study juvenile survival had the highest elasticity followed by time to first reproduction. Thus a given impact

Table 1. Percent changes of individual traits and population growth rate $(\lambda)$ and proportional contribution of individual traits (\%) to changes in population growth rate $(\lambda)$ of Folsomia candida on Askov sandy loam soil, based on Caswel (1996) and Levin et al. (1996)

\begin{tabular}{|c|c|c|c|c|c|c|c|c|c|}
\hline \multirow[t]{2}{*}{ Concentration (mg NP/kg dw) } & \multicolumn{5}{|c|}{$\%$ changes of } & \multicolumn{4}{|c|}{ Contribution $(\%)$} \\
\hline & $\lambda$ & $t_{\mathrm{j}}$ & $N$ & $t_{\mathrm{a}}$ & $S_{\mathrm{a}}$ & $t_{\mathrm{j}}$ & $N$ & $t_{\mathrm{a}}$ & $S_{\mathrm{a}}$ \\
\hline 8 & 0.46 & -2.53 & 22.34 & -1.97 & -7.5 & 35.00 & 61.41 & 1.33 & 2.26 \\
\hline 16 & 1.55 & 0 & 27.59 & 0.56 & 2.27 & 0 & 98.57 & 0.53 & 0.90 \\
\hline 24 & 1.24 & 1.04 & 15.99 & 0.18 & -1.27 & 24.31 & 74.85 & 0.21 & 0.63 \\
\hline 32 & 0.71 & 0.33 & 10.18 & 0.49 & -0.04 & 13.28 & 85.66 & 1.02 & 0.04 \\
\hline
\end{tabular}


on juvenile survival probability and time to first reproduction would be expected to have much greater consequences for population dynamics than would a similar proportional impact on adult survival, fecundity or time between broods. Whereas juvenile survival had a very high elasticity; adult survival had the lowest elasticity of all traits. However, since neither of these traits was influenced by $\mathrm{NP}$ (below the highest treatment concentration) they did not contribute to changes in population growth rate. In contrast, fecundity was sensitive to NP exposure, but because of its low elasticity, the consequences of changes in fecundity for $\lambda$ were minimal.

Similar effects of NP have been observed in the polychaete, Capitella sp. I (Hansen et al., 1999) in which $\lambda$ was not significantly affected although a stimulatory effect on brood size was observed. Several other studies have also indicated a lower sensitivity of $\lambda$ compared to individual-level endpoints such as growth and reproduction (e.g. Stark et al., 1997). Widarto et al. (2004) found negative effects of NP on fecundity of the earthworm D. octaedra, but the resulting decline in $\lambda$ was not significant. Bechmann (1999) did not detect an effect of NP on $\lambda$ of the marine copepod Tisbe battagliai even though only $6 \%$ of the juveniles reached maturity at $62 \mu \mathrm{g} \mathrm{NP} / 1$. Apparently, the survivors were able to produce enough offspring to increase the size of the population compared to the parent generation. Walthall and Stark (1997) suggested that species with high reproductive rates may have an ability to compensate for the loss of individuals caused by toxicants such that effects on $\lambda$ are minimized or nullified.

Both Kammenga et al. (1996) and Moe et al. (2001) demonstrated that reductions in population growth rate are not determined by the most sensitive life-cycle traits. Klok and de Roos (1996) suggested that the relationships between effects at the individual- and population-levels are not always straightforward and are sometimes counterintuitive. These results highlight the difficulty of using single life-history traits as simple proxies for populationlevel effects.

\subsection{Interspecies differences in sensitivity}

Negative effects of NP on various life-history traits at sublethal levels have been recorded in many studies with a variety of taxa; however there do not seem to be any general patterns among species as to which traits are the most/least sensitive. Some studies observed negative effects on growth and development but not on other traits (Widarto et al., 2004); other studies observed effects on reproduction only (e.g. Hood et al., 2000; Bettinetti et al., 2002), whereas effects of NP on other measured life-history traits were not detected. Exposure to sublethal concentrations of NP did not influence Chironomus riparius emergence success (Bettinetti and Provini, 2002), Corophium volutator sex ratio (Brown et al., 1999), various life-history traits of Tisbe battagliai (Bechmann, 1999), growth or reproduction in Chironomus tentans (emergence, sex ratio, fecundity, and egg viability) (Kahl et al., 1997), or fecundity or sex ratio in Daphnia magna (Baldwin et al., 1997).

The toxicity of NP in the present study (juvenile LC50 between 32 and $40 \mathrm{mg} / \mathrm{kg}$ ) was equal to or slightly higher than that observed in other similar studies (such as Madsen et al., 1998; Gejlsberg et al., 2001; Krogh et al., 1997). Several factors may have increased the toxicity observed in the present study compared to earlier work. Our study was initiated with early-stage juveniles (1-2 days old) whereas the other studies generally employed very latestage juveniles or subadults (10-12 days old that will mature within 5-3 days), which is a standard test procedure (Riepert and Kula, 1996). Young juveniles are very active metabolically and physiologically since they are in progressive development and differentiation as demonstrated by Holmstrup and Krogh (1996) with F. fimetaria. In addition, younger animals generally have smaller body sizes than older individuals, and thus a higher surface-to-volume ratio resulting in more rapid rates of chemical uptake. Effects of body size may contribute to differences in sensitivity both within and among species (cf. Widarto et al., 2004; Gejlsberg et al., 2001).

A second factor contributing to differences in organism sensitivity among studies is the soil organic content. As a hydrophobic chemical, NP tends to bind to organic material in the soil so that its concentration in porewater may decrease, thereby reducing its bioavailability. The application of NP to soil via sludge is likely to increase soil organic content and thereby reduce the availability and toxicity of NP. The addition of sludge to soil (sludge:soil ratio, 1:20) increased the LC50 by a factor of 1.5 (Gejlsberg et al., 2001). In contrast, Scott-Fordsmand and Krogh (2003) found that adding NP-contaminated sewage sludge into soil did not significantly reduce the toxicity of NP to F. fimetaria.

\subsection{Why might NP show non-monotonic concentration- response relationships?}

\subsubsection{Endocrine disruption}

In the present study, clear stimulatory responses to NP were seen for growth and fecundity at concentrations a factor of 2.5 below those leading to complete juvenile mortality. Stimulatory effects of NP on growth and reproduction at low concentrations may be associated with the estrogenic characteristics that have been reported for this chemical. Studies of vertebrates have suggested (e.g. Yadetie et al., 1999) that NP imitates natural (endogenous) estrogen (E2), binds to and activates the estrogen receptor (ER) leading to estrogenic effects. Stimulation of certain life-history traits is likely to occur after exposure to a xenoestrogen since E2 normally stimulates tissue growth by promoting cell proliferation and enlargement in addition to initiating protein synthesis (e.g. Colerangle and Roy, 1996). In insects, juvenoids are juvenile hormones $(\mathrm{JH})$ responsible for growth and the metamorphosis of juveniles into adults (Le 
Blanc et al., 1999). Their action is mediated by specific receptors, and they may be susceptible to binding by xenoestrogens (WHO/IPCS, 2002).

Stimulatory effects of NP on animals have been observed at subcellular, cellular and organ levels (e.g. Hemmer et al., 2001; Yokota et al., 2001). Stimulation of animal life-history traits (especially growth and fecundity) has been detected in at least three studies (Hansen et al., 1999; Hoss et al., 2002; Duft et al., 2003). In a field study, Krogh et al. (1996) detected an increased number of Collembola in the presence of sewage sludge contaminated with $150 \mathrm{mg}$ $\mathrm{NP} / \mathrm{kg} \mathrm{dw}$ soil, particularly in the lower layer $(10-20 \mathrm{~cm}$ in depth).

A common response of animals encountering xenoestrogens is an increase in vitellogenin production. All egg-laying animals, including invertebrates and insects, produce vitellogenin needed to initiate the creation of yolk protein (Byrne et al., 1989). Hill et al. (2003) reported that NP caused vitellogenin induction, delayed sexual maturation, caused production of a small percentage of ova-testes, led to a female biased sex ratio, and impaired reproductive capacity of zebra fish (Danio rerio). Vitellogenin production and other developmental processes, molting, embryo development, and ovulation are regulated by ecdysteroids. As for juvenoids, NP may have bound to and activated the ecdysteroid specific receptor eliciting enhanced effects on reproduction.

\subsubsection{Hormesis}

A second explanation for the stimulatory effects of NP is hormesis. Stebbing (1982) defined hormesis as a stimulatory response after low-dose exposure followed by inhibition at higher doses, considered to result from overcompensation to changes in homeostasis caused by stress. He suggested that the phenomenon, especially hormetic growth, represents an adaptation of the growth control mechanism due to overcorrection by the organism in overcoming the stress (Stebbing, 1998). Calabrese and Baldwin (2001) concluded that most of the hormetic dose-response relationships reported in the literature support the idea of overcompensation stimulation following an initial period of disruption instead of a direct stimulation. The period of disruption at the beginning of exposure is a critical factor in judging hormetic cases.

Calabrese and Baldwin (1998) suggested that not all stimulatory effects can be considered as hormesis, and they proposed some criteria that can be used to confirm the occurrence of hormesis, such as number of doses below the no observed effects level (NOEL), whether NOEL is determined or not, number of doses that are statistically significant, and the magnitude of the response. We observed that with five doses below NOEL, two doses were significantly different from the control; stimulation was around $11-33 \%$ and $10-27 \%$ greater than the control for growth and fecundity, respectively. In relation to the criteria proposed by Calabrese and Baldwin (1998) we propose that the stimulatory effect observed in our study can be categorized as a low to moderate hormesis. We note that stimu- lation of growth in our study first became apparent after about 10 days of exposure, and that after 30 days of exposure no differences in body size between groups were detectable (Figure 1). Likewise, of six broods recorded, stimulation of fecundity was detectable for the first four broods, but was not significantly different from control for the last two broods. These results may indicate that the exposed collembolans acclimated to NP exposure during the course of the experiment, after being slightly affected at the beginning of the exposure period.

Whether stimulation of growth (or other life-history traits) indicates that a chemical acts as a disruptor of specific hormonal processes or whether it results from general overcompensation to low levels of stress can be difficult to determine in practice yet may have importance in interpreting the effects of chemicals on organisms. However, of most importance for ecological risk assessment is the extent to which such effects on life-history traits - whatever their underlying biochemical mechanism - result in effects at the population level.

\section{Conclusions}

In conclusion, the presence of NP in soil stimulated body growth rate and fecundity of the parthenogenetic springtail, F. candida, but did not affect population growth rate, $\lambda$. Effects of NP on fecundity contributed $80 \%$ of the observed effect on $\lambda$. However, due to the low elasticity of $\lambda$ to changes in fecundity, changes in this life-history trait did not result in a significant effect on $\lambda$. The present study demonstrates the kinds of insights that can be gained by integrating effects of toxicants at the individual level to effects on population growth rate, particularly when life-history traits exhibit variable and nonlinear concentration-response curves. We emphasize that this study was conducted under controlled laboratory conditions, and other factors, such as density-dependent interactions, predators, initial population structure, habitat features, etc., may have a critical influence on the dynamics of field populations and need to be considered when assessing the likely effects of toxic chemicals in nature.

Acknowledgments - This study was supported financially by Quality for Undergraduate Education (QUE) Project under World Bank Loan Scheme to Indonesian Government as a doctoral stipend to THW. Most of the work was conducted at the Department of Life Sciences and Chemistry, Roskilde University, Denmark and Department of Terrestrial Ecology (TERI), National Environmental Research Institute, Denmark. We thank Z. Gavor, K.K. Jacobsen, E. Jørgensen, T. Sørensen, L. Birkso, and L. Maarup for helping with laboratory work. 


\section{References}

Baldwin, W. S., Graham, S. E., Shea, D., LeBlanc, G. A., 1997. Metabolic androgenization of female Daphnia magna by the xenoestrogen 4-nonylphenol. Environ. Toxicol. Chem. 16 (9): $1,905-1,911$.

Bechmann, R. K., 1999. Effect of the endocrine disrupter nonylphenol on the marine copepod Tisbe battagliai. Sci. Total Environ. 233: 33-46.

Bettinetti, R., Provini, A., 2002. Toxicity of 4-nonylphenol to Tubifex tubifex and Chironomus riparius in 28-day wholesediment tests. Ecotox. Environ. Saf. 53 (1): 113-121.

Bettinetti, R., Cuccato, D., Galassi, S., Provini, A., 2002. Toxicity of 4-nonylphenol in spiked sediment to three populations of Chironomus riparius. Chemosphere 46 (2): 201-207.

Brown, R. J., Conradi, M., Depledge, M. H., 1999. Long-term exposure to 4-nonylphenol affects sexual differentiation and growth of the amphipod Corophium volutator (Pallas, 1766). Sci. Total Environ. 233 (1-3): 77-88.

Byrne, B. M., Gruber, M., Ab, G., 1989. The evolution of egg yolk proteins. Prog. Biophys. Mol. Biol. 53, 33-69.

Calabrese, E. J., Baldwin, L. A., 1998. Hormesis as a biological hypothesis. Environ. Health Perspect. 106 (Suppl. 1): 357-362.

Calabrese, E. J., Baldwin, L. A., 2001. U-shaped dose-responses in biology, toxicology, and public health. Annu. Rev. Public Health 22: 15-33.

Calow, P., Sibly, R. M., 1990. A physiological-basis of population processes-ecotoxicological implications. Funct. Ecol. 4: 283-288.

Caswell, H., 1989. Analysis of life table response experiments 1. Decomposition of effects on population growth rate. Ecol. Modeling 46: 221-237.

Caswell, H., 1996. Analysis of life table response experiments. 2. Alternative parameterizations for size-and stage-structured models. Ecol. Modeling 88: 73-82.

Caswell, H., 2001. Matrix Population Models: Construction, Analysis, and Interpretation, second edition. Sinauer Assoc., Sunderland, MA, USA.

Colerangle, J. B., Roy, D., 1996. Exposure of environmental estrogenic compound nonylphenol to noble rats alters cell-cycle kinetics in the mammary gland. Endocrine 4 (2): 115-122.

Duft, M., Schulte-Oehlmann, U., Weltje, L., Tillmann, M., Oehlmann, J., 2003. Stimulated embryo production as a parameter of estrogenic exposure via sediments in the freshwater mudsnail Potamopyrgus antipodarum. Aquat. Toxicol. 64 (4): 437-449.

Forbes, V. E., Calow, P., Sibly, R. M., 2001. Are current species extrapolation models a good basis for ecological risk assessment? Environ. Toxicol. Chem. 20: 442-447.

Gejlsberg, B., Klinge, C., Samsoe-Petersen, L., Madsen, T., 2001. Toxicity of linear alkylbenzene sulfonates and nonylphenol in sludge-amended soil. Environ. Toxicol. Chem. 20 (12): 2,709-2,716.

Granmo, A., Ekelund, R., Magnusson, K., Berggren, M., 1989. Lethal and sublethal toxicity of 4-nonylphenol to the common mussel (Mytilus edulis L.). Environ. Pollut. 59 (2): 115-127.
Hansen, F. T., Forbes, V. E., Forbes, T. L., 1999. Effects of 4-nonylphenol on life-history traits and population dynamics of a polychaete. Ecol. Appl. 9 (2): 482-495.

Hemmer, M. J., Hemmer, B. L., Bowman, C. J., Kroll, K. J., Folmar, L. C., Marcovich, D., Hoglund, M. D., Denslow, N. D., 2001. Effects of p-nonylphenol, methoxychlor, and endosulfan on vitellogenin induction and expression in sheepshead minnow (Cyprinodon variegatus). Environ. Toxicol. Chem. 20 (2): 336-343.

Hill, J., Robert, L., Janz, D. M., 2003. Developmental estrogenic exposure in zebrafish (Danio rerio): I. Effects on sex ratio and breeding success. Aquat. Toxicol. 63 (4): 417-429.

Holmstrup, M., Krogh, P. H., 1996. Effects of an anionic surfactant, linear alkylbenzene sulfonate, on survival, reproduction and growth of the soil-living collembolan Folsomia fimetaria. Environ. Toxicol. Chem. 15 (10): 1,745-1,748.

Hood, T. E., Calabrese, E. J., Zuckerman, B. M., 2000. Detection of an estrogen receptor in two nematode species and inhibition of binding and development by environmental chemicals. Ecotox. Environ. Saf. 47 (1): 74-81.

Hoss, S., Juttner, I., Traunspurger, W., Pfister, G., Schramm, K. W., Steinberg, C. E. W., 2002. Enhanced growth and reproduction of Caenorhabditis elegans (Nematoda) in the presence of 4-nonylphenol. Environ. Pollut. 120 (2): 169-172.

Jensen, A., Forbes, V. E., Parker, E. D., 2001. Variation in cadmium uptake, feeding rate and life-history effects in the gastropod Potamopyrgus antipodarum. Linking toxicant effects on individuals to the population level. Environ. Toxicol. Chem. 20: 2,503-2,513.

Johnson, A. C., White, C., Besian, T. J., Jurgens, M. D., 1998. The sorption potential of octylphenol, a xenobiotic oestrogen, to suspended and bed-sediments collected from industrial and rural reaches of three English rivers. Sci. Total. Environ. 210, 271-282.

Kahl, M. D., Makynen, E. A., Kosian, P. A., Ankley, G. T., 1997. Toxicity of 4-nonylphenol in a life-cycle test with the midge Chironomus tentans. Ecotox. Environ. Saf. 38 (2): 155-160.

Kammenga, J. E., Busschers, M., van Straalen, N. M., Jepson, P. C., Bakker, J., 1996. Stress induced fitness reduction is not determined by the most sensitive life-cycle trait. Funct. Ecol. 10: 106-111.

Klok, C., de Roos, A. M., 1996. Population level consequences of toxicological influences on individual growth and reproduction in Lumbricus rubellus (Lumbricidae, Oligochaeta). Ecotox. Environ. Saf. 33: 118-127.

Krogh, P. H., Holstrump, M., Jensen, J., Petersen, S. O., 1996. Oekotoksikologisk vurdering af spildevandsslam i landbrugsjord. [Ecological assessment of sewage sludge on farm land-Report from the Danish EPA; in Danish with English summary]. Arbejdsrapport No. 43, p. 53. Miljoe-og Energiminisisteriet Miljoestyrelsen.

Krogh, P. H., Holmstrup, M., Jensen, J., Petersen, S. O., 1997. Ecotoxicological Assessment of Sewage Sludge in Agricultural Soil. Working Report 69. Danish Environmental Protection Agency, Copenhagen, Denmark.

Laskowski, R., 2001. Why short-term bioassays are not meaningful-Effects of a pesticide (imidacloprid) and a metal (cadmium) on pea aphids (Acyrthosiphon pisum Harris). Ec- 
otoxicology 10 (3): 177-183.

Le Blanc, G., Campbell, P., den Besten, P., Brown, R., Chang, E., Coats, J., deFur, P., Dhadialla, T., Edwards, J., Riddiford, L., Simpson, M., Snell, T., Thorndyke, M., Matsumura, F., 1999. In: deFur, P., Crane, M., Ingersoll, C., Tattersfield, L. (Eds.), Endocrine Disruption in Invertebrates: Endocrinology, Testing and Assessment. SETAC Press, Pensacola, FL, pp. 23-106.

Levin, L., Caswell, H., Bridges, T., DiBacco, C., Cabrera, D., Plaia, G., 1996. Demographic responses of estuarine polychaetes to pollutants: life table response experiments. Ecol. Appl. 6: 1,295-1,313.

Madsen, T., Winther-Nielsen, M., Samsøe-Petersen, L., 1998. Effects of Organic Chemicals in Sludge Applied to Soil. Environmental Project 432. Danish Environmental Protection Agency, Copenhagen, Denmark.

Maguire, R. J., 1999. Review of the persistence of nonylphenol and nonylphenol ethoxylates in aquatic environments. Water Qual. Res. J. Can. 34: 37-38.

Moe, S. J., Stenseth, N. C., Smith, R. H., 2001. Effects of a toxicant on population growth rates: sublethal and delayed responses in blowfly populations. Funct. Ecol. 15 (6): 712-721.

Nimrod, A. C., Benson, W. H., 1996. Estrogenic responses to xenobiotics in channel catfish (Ictalurus punctatus). Mar. Environ. Res. 42 (1-4): 155-160.

Riepert, F., Kula, C., 1996. Development of laboratory methods for testing effects of chemicals and pesticides on Collembola and earthworms. Mittelungen aus der Biologischen Bundesanstalt für Land-und Forstwirtschaft, p. 82.

Scott-Fordsmand, J. J., Krogh, P. H., 2003. The influence of application form on the toxicity of nonylphenol to Folsomia fimetaria (Collembola: Isotomidae). Ecotox. Environ. Saf. 58 (3): 294-299.

Scott-Fordsmand, J. J., Krogh, P. H., Weeks, J. M., 1997. Sublethal toxicity of copper to a soil-dwelling springtail (Folsomia fimetaria) (Collembola: Isotomidae). Environ. Toxicol. Chem. 16: 2,538-2,542.

Sibly, R. M., Hansen, F. T., Forbes, V. E., 2000. Confidence intervals for population growth rate of organisms with twostage life histories. Oikos 88 (2): 335-340.

Stark, J. D., Banken, J. A. O., 1999. Importance of population structure at the time of toxicant exposure. Ecotox. Environ. Saf. 42 (3): 282-287.

Stark, J. D., Tanigoshi, L., Bounfour, M., Antonelli, A., 1997. Reproductive potential: its influence on the susceptibility of a species to pesticides. Ecotox. Environ. Saf. 37 (3): 273-279.

Stebbing, A. R. D., 1982. Hormesis - the stimulation of growth by low levels of inhibitors. Sci. Total Environ. 22 (3): 213-234.

Stebbing, A. R. D., 1998. A theory for growth hormesis. Mutat. Res. 403 (1-2): 249-258.

Sverdrup, L. E., Krogh, P. H., Nielsen, T., Stenersen, J., 2002. Relative sensitivity of three terrestrial invertebrate tests to polycyclic aromatic compounds. Environ. Toxicol. Chem. 21: 1,927-1,933.

Van Gestel, C. A. M., Hensbergen, P. J., 1997. Interaction of Cd and $\mathrm{Zn}$ toxicity for Folsomia candida Willem (Collembola:
Isotomidae) in relation to bioavailability in soil. Environ. Toxicol. Chem. 16 (6): 1,177-1,186.

Van Straalen, N. M., Schobben, J. H., de Goede, R. G. M., 1989. Population consequences of cadmium toxicity in soil microarthropods. Ecotoxicol. Environ. Saf. 17: 190-204.

Walthall, W. K., Stark, J. D., 1997. A comparison of acute mortality and population growth rate as endpoints of toxicological effect. Ecotoxicol. Environ. Saf. 37: 45-52.

WHO/IPCS (World Health Organization/International Petroleum Chemical Society), 2002. In: Damstra, T., Barlow, S., Bergman, A., Kavlock, R., Van Der Kraak, G. (Eds.), Global Assessment of the State-of-the-Science of Endocrine Disruptors. WHO/IPCS/EDC/02.2. World Health Organization, Geneva, Switzerland.

Widarto, T. H., Holmstrup, M., Forbes, V. E., 2004. The influence of nonylphenol on the life-history of earthworm Dendrobaena octaedra Savigny: linking effects from individualto the population-level. Ecotox. Environ. Saf. 58 (2): 147-159.

Yadetie, F., Arukwe, A., Goksoyr, A., Male, R., 1999. Induction of hepatic estrogen receptor in juvenile Atlantic salmon in vivo by the environmental estrogen, 4-nonylphenol. Sci. Total Environ. 233 (1-3): 201-210.

Yokota, H., Seki, M., Maeda, M., Oshima, Y., Tadokoro, H., Honjo, T., Kobayashi, K., 2001. Life-cycle toxicity of 4-nonylphenol to medaka (Oryzias latipes). Environ. Toxicol. Chem. 20 (11): 2,552-2,560. 